\section{SCI 论文投稿常见状态}

张真真

一般 SCI 论文投稿都是通过杂志 主页在线投稿, 投稿成功后会出现哪 些常见状态呢? 针对这一问题我们做 一个专门的细致总结, 可以让作者投 稿后及时了解自己文章的进展, 对一 些写作新手来说尤为有用。了解投稿 状态一是图个心安, 二是知道文章状 态后可以早做准备, 有的放矢。

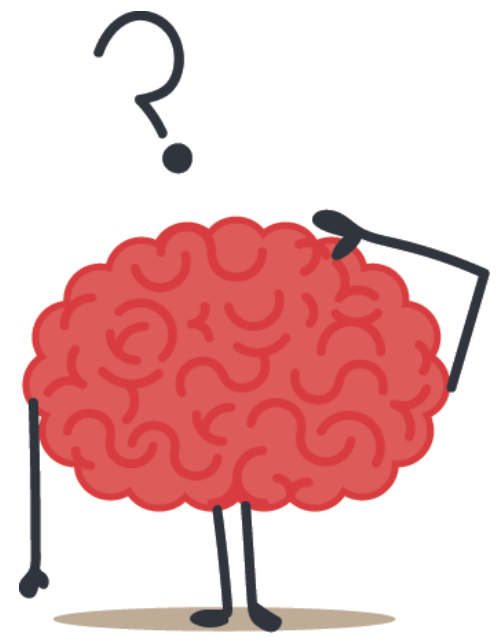

Submitted to journal

当论文上传成功后, 会自然生成 这个状态, 代表论文已成功上传至杂 志社。

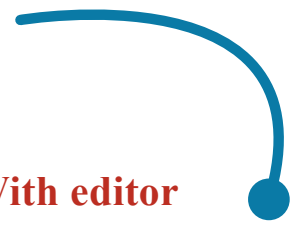

上传成功的论文一般会先经过编辑审 稿这一关, 通过后编辑会分配给适合的审 稿人进人审稿程序。这一关都过不了的话, 论文就会比较悲剧, 直接拒稿, 基本没有 可参考的审稿意见, 也就是编辑的客套话, 只能改投其他杂志。

注: 有的杂志可能在 With editor 之 前出现 Submissions being processed 的状 态, 这个意思是文章还未到达编辑那里, 可能处在格式或语言审查编辑那里, 如果 格式有问题或者语言问题太大, 可能会退 稿, 不过退稿也不用担心, 把格式或语言 修改好可以继续投稿, 不会影响下一步的 审稿过程。 编辑会邀请相应的审稿人进行同行评 议, 这个状态就是邀请审稿人的状态。 有的杂志, 编辑会从作者在线上传稿 件时提供的审稿人中邀请, 有的可能 是编辑直接另寻审稿人。有时候这个 过程会持续一段时间, 尤其是一些比 较偏门的领域。 


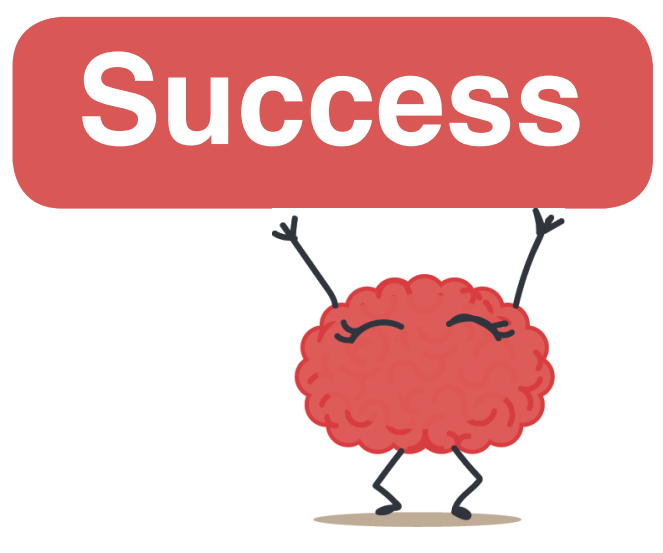

Accepted

文章接收, 当出现这个状态时, 基本上就大功告成了, 后续也就是校 稿、版权事宜等待出版了。当然如果 不认真对待编辑和审稿人提出的意 见，也有可能存在修回后被拒稿的可 能。

\section{Revision submitted to journal}

修回的稿件重新提交等待编辑处理的过 程。这个过程有时候编辑会直接做决定是否 提出的问题。 接收, 有的会发给审稿人进行二次审稿, 不 管怎样, 都要认真对待每次编辑或者审稿人

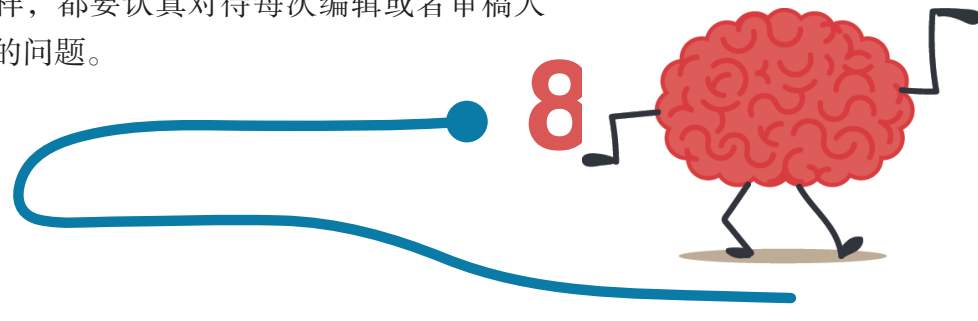

\section{Minor/Major Revision/ Reject but encourage to resubmit}

到了这一步, 如果出现上述三种 状态, 那么文章只要细致修改, 都有 接收的可能, 到了这一步, 千万不能 马虎, 切记切记! 有的作者急着毕业, 没有根据修改意见认真修改，那么修 改后投回也很可能被拒稿。修回的稿 件有可能会有二次、三次的再修改，

\section{Decision in process}

这个状态是审稿人的意见已经发 至编辑手中, 编辑进行考量评估的阶 段, 这个阶段决定稿件是给予修改还 是拒稿, 时间不定。如果论文质量非 常高的话, 也有可能是直接接受, 当 然这种情况非常的少见。

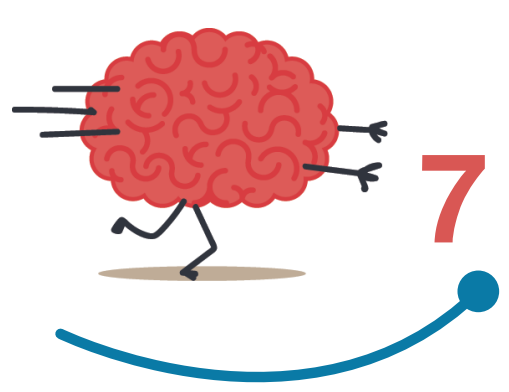
这个时候千万不能泄气，好好对待审 稿人的每条意见。

如果是拒稿但不鼓励再投, 虽然 有审稿意见, 但是杂志不会再接收这 个稿件, 这种情况只能换投其他杂志。
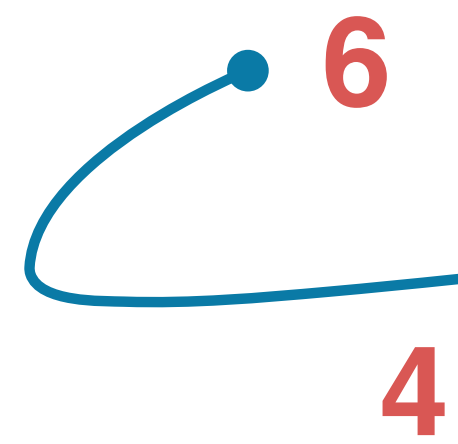

\section{Under review}

这个状态是审稿人已接受审稿, 正处于审稿中的状态, 不同杂志审稿 时间不同, 快的可能一个月之内, 慢 的三个月甚至半年也有可能, 一般来 说在 1-2 个月之内。因为有时候存在 被邀请的审稿人拒绝审稿, 那么编辑 就要另寻审稿人, 这中间也会花费一 段时间。

\section{Required reviews completed}

审稿结束, 等待编辑处理的过程。 一般来说这段时间不会太长, 甚至有 的杂志没有这个状态。 